\title{
The seroprevalence of human brucellosis in different age groups patients and other associated risk factors in Duhok, Iraq
}

La seroprevalencia de la brucelosis humana en pacientes de diferentes grupos de edad y otros factores de riesgo asociados en Duhok, Iraq

Author:

Mahde S Assafi ${ }^{1}$

Muslim A Allu ${ }^{2}$

Ibtesam S Abdulrahman ${ }^{3}$

Mohammad I Al-Berfkani ${ }^{4}$

\section{SCIENTIFIC RESEARCH}

How to cite this paper:

Assafi M, Allu M, Abdulrahman I, Al-Berfkani M. The seroprevalence of human brucellosis in different age groups patients and other associated risk factors in Duhok, Iraq, Duhok, Iraq. Innovaciencia. 2019; 7(2) 1-7.

http://dx.doi.org/10.15649/2346075X.479

Reception date:

Received: 15 August 2018

Accepted: 25 November 2018

Published: 28 December 2018

Keywords:

Brucellosis; Rose Bengal test; Seroprevalence; Risk factors, Iraq.

\section{ABSTRACT}

Introduction: Brucellosis is a zoonotic disease contributing to significant health and economic problems worldwide. The aim of this study was to investigate the seroprevalence and the associated risk factors of brucellosis among people admitted to Azadi general hospital, Duhok, Iraq. Patients and Methods: A total of 1283 patient blood samples (603 males and 680 females) were collected through the period of January 2017 to December 2017 from people at different age groups admitting Azadi general hospital, Duhok, Iraq. All collected sera were screened for the seroprevalence of Brucella using Rose Bengal plate test kit. Results: Among the 1283 blood samples, the overall seroprevalence of brucellosis was $17.8 \%$. The highest rate was recorded in age group between 21-30 years $(22.7 \%)$ and the different distribution of human brucellosis among age groups was statistically significant $(\mathrm{p}=0.0076)$. The frequency of brucellosis in females (20\%) was significantly higher than males $(15.3 \%)(p=026)$. The distribution of brucellosis according to the seasonal changes was statistically significant $(p=0.003)(25.64 \%$ in July and $9.75 \%$ in December). Conclusions: The incidence of the brucellosis is high, and it remains a challenging health problem. The age, gender, and seasonal changes are considered as important risk factors for the distribution of the diseases. Surveillance programs and active screening for brucellosis are essential to prevent, control, and to reduce the incidence of the brucellosis.

${ }^{1}$ Department of Biology, School of Sciences, University of Duhok, Duhok, Iraq, email: mahdy.assafi@yahoo.co.uk.

2 Department of Medical Laboratory Technology, Duhok Polytechnic University, Duhok, Iraq.

3 Department of Pharmaceutic, College of Pharmacy, University of Duhok, Kurdistan region, Iraq.

${ }^{4}$ Department of Medical Laboratory Technology, Duhok Polytechnic University, Duhok, Iraq. 


\section{INTRODUCCTION}

Brucellosis is a systemic infectious disease transmitted from certain animals to human ${ }^{(1)}$. This zoonotic disease is endemic in Iraq and worldwide (2). It has various terms such as Malta fever, undulant fever and Mediterranean fever ${ }^{(3)}$. More than 0.5 million human brucellosis cases are reported annually and in some countries, the incidence rate is more than 10 cases per 100,000 population $\frac{4,5)}{2}$. The most pathogenic and invasive species of Brucella that infect human are B. melitensis, followed by B. suis, B. abortus and B. canis ${ }^{(3,6)}$. Human acquires brucellosis through direct contact with infected animals or their products 7 . Brucellosis in human is manifested by a various range of clinical symptoms and signs and the undulant fever is the most important symptom (3). The symptoms of the brucellosis in the positive serological tests results include sweating, weakness, and myalgia ${ }^{(4)}$. Other initial symptoms may include headache, fatigue, weight loss, anorexia, muscle and joints pain. Furthermore, asymptomatic infections can also occur in humans ${ }^{(1)}$. This zoonotic disease is considered serious and sometimes chronic disease that contributing to significant health and economic

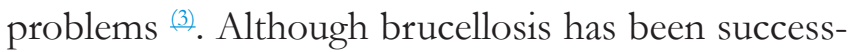
fully eradicated in many countries, it is still endemic in many parts of the world $\stackrel{(8,9)}{2}$ such as the countries of Eastern Mediterranean Region, Middle East, Africa, Mediterranean basin, central Asia, and Latin America. Most parts of Iraq are still endemic for the disease in animals as well as humans ${ }^{(10)}$. Therefore, identifying the risk factors of brucellosis is very important to understand the nature of the disease and its transmission routes for the eradication of human brucellosis. Thus, the aims of this study were to assess the present status of seroprevalence of brucellosis among patient populations in Duhok, Iraq, and to investigate the significant effects of some factors such as sex, age, and seasonal variation on the distribution of brucellosis cases.

\section{PATIENTS AND METHODS}

\section{Sample collection}

A total of 1283 blood samples were collected from patients at different age groups who attended Azadi general hospital, Duhok, Kurdistan region, Iraq through the period from January 2017 to December 2017. All patients with clinical suspicion of brucellosis, who would normally present for laboratory-based brucellosis testing, were included in this study. Of these, 603 (47\%) were male patients and 680 (53\%) were females. About $5 \mathrm{ml}$ of blood sample was collected in a sterile vacutainer from each patient. Then, the blood samples were centrifuged at $2000 \mathrm{rpm}$ for five minutes to obtain the serums. The serum sample of each patient was transferred into $1 \mathrm{ml}$ microtubes and aliquots were prepared (to prevent the repeated freezing-thawing process) and stored at $-20^{\circ} \mathrm{C}$ until performing the serological test.

\section{Rose Bengal test}

All collected sera were screened for the presence of antibodies against Brucella using the commercially available Rose Bengal plate test kit (Institute-Pourquie/France) as recommended by the manufacturer. Briefly, $30 \mu \mathrm{L}$ of plain serum were dispensed on a white glossy ceramic tile and mixed with an equal volume of the Rose Bengal test antigen. The serum and the antigen were mixed thoroughly and rapidly at room temperature for 4 minutes and any visible agglutination was taken as a positive result. Otherwise, the result was considered as negative $\frac{(11,12)}{}$.

\section{Data analysis}

All statistical analysis was performed using the SPSS 20 software. Chi-squared test was used to assess the associations between variables. $\mathrm{P}$ value of $<0.05$ was considered as significant. 


\section{RESULTS}

\section{Seroprevalence of brucellosis in human}

The results revealed that anti-brucella antibodies were detected in 228 out of 1283 blood samples representing the overall $17.8 \%$ of the seroprevalence of brucellosis (Table 1).
The seropositivity of brucellosis was varied in different age groups (Table 1). The highest rate $(22.7 \%)$ was recorded in age group between $21-30$ years. The elderly patients (older than 50 years) showed less prevalence of brucellosis $(11.5 \%)$. The different distribution of human brucellosis among these two age groups was statistically significant $(\mathrm{p}=0.0076)$.

\section{Age distribution of brucellosis}

Table 1. Age distribution of brucellosis

\begin{tabular}{|c|c|c|}
\hline Age group (Years) & samples & No. of Positive ( $\%)$ \\
\hline$\leq 10$ & 169 & $21(12.4)$ \\
\hline $11-20$ & 234 & $41(17.5)$ \\
\hline $21-30$ & 273 & $62(22.7)$ \\
\hline $31-40$ & 283 & $59(20.8)$ \\
\hline $41-50$ & 194 & $30(15.5)$ \\
\hline$>51$ & 130 & $15(11.5)$ \\
\hline Total & 1283 & $228(17.8)$ \\
\hline
\end{tabular}

\section{Gender difference of brucellosis}

In the present study, there was a significant difference $(\mathrm{p}=026)$ of the frequency of brucellosis in females patients $(136 ; 20 \%)$ than males $(92 ; 15.3 \%)$ (Table 2$)$. In males, the highest percentage of infected patients was at age group $21-30$ years $(27 ; 21.4 \%)$ and the lowest $(7 ; 8.97 \%)$ was at age $\leq 10$ years. There was a significant difference found between these two age groups $(\mathrm{p}=0.020)$. In females, the age group 21-30 years showed highest infection rate $(35 ; 23.81 \%)$ and the lowest infection rate was at age group $>51$ years $(8 ; 14.04 \%)$. But the differences between these two age groups were statistically not significant $(p=0.124)$.

Table 2. Sex distribution of brucellosis

\begin{tabular}{cclcc}
\hline Age group (Years) & \multicolumn{2}{c}{ Male } & \multicolumn{2}{c}{ Female } \\
& No. of samples & No. of positive (\%) & No. of samples & No. of positive (\%) \\
\hline$\leq 10$ & 78 & $7(8.97)$ & 91 & $14(15.38)$ \\
$11-20$ & 94 & $12(12.8)$ & 140 & $29(20.71)$ \\
$21-30$ & 126 & $27(21.4)$ & 147 & $35(23.81)$ \\
$31-40$ & 134 & $25(18.7)$ & 149 & $34(22.82)$ \\
$41-50$ & 98 & $14(14.3)$ & 96 & $16(16.67)$ \\
$>51$ & 73 & $7(9.59)$ & 57 & $8(14.04)$ \\
Total & 603 & $92(15.3)$ & 680 & $136(20)$ \\
\hline
\end{tabular}




\section{Seasonal distribution of brucellosis}

Seasonal variations have marked epidemiological interest in brucellosis. In this study, the rate of brucellosis ranged from $9.75 \%$ in December to $25.64 \%$ in July $(p=0.0086)$ (Table 3). The distribution of brucellosis according to the seasonal changes was statistically significant $(p=0.003)$.

Table 3. Seasonal distribution of brucellosis

\begin{tabular}{ccc}
\hline Months & No. of samples & No. of positive (\%) \\
January & 95 & $18(18.95)$ \\
February & 94 & $12(12.77)$ \\
March & 81 & $10(12.35)$ \\
April & 112 & $16(14.29)$ \\
May & 99 & $16(16.16)$ \\
June & 169 & $42(24.85)$ \\
July & 156 & $40(25.64)$ \\
August & 124 & $28(22.58)$ \\
September & 101 & $16(15.84)$ \\
October & 91 & $14(15.38)$ \\
November & 79 & $8(10.13)$ \\
December & 82 & $8(9.756)$ \\
Total & 1283 & $228(17.77)$ \\
\hline
\end{tabular}

\section{DISCUSSION}

Brucellosis is a zoonotic disease that is transmittable from animals to human. Although brucellosis has been controlled in most developed countries, it remains an important public health problem in developing countries. The Rose Bengal test (RBT) is a rapid screening test and although it was designed originally for screening use in veterinary medicine, but is now often used for the diagnosis of human brucellosis 13,14$)$. The sensitivity of the Rose Bengal plate test is more than $99 \%$, and the rate of false-negative results is infrequent $\stackrel{(15)}{ }$. The RBT is the most common serological test used in Iraq for detection of human brucellosis.
The seroprevalence of brucellosis in the current study was $17.8 \%$. The human brucellosis rates were varied in different studies in Iraqi provinces ${ }_{-}(2,16)$. The current rate was high compared to previous studies in the region. In 2015, the prevalence rate was 9.5\% in Erbil and 13.2\% in Mosul (2). However, other studies showed higher rates in the country. In 2015, high rates of a positive result by RBT were reported among people in Al-Sulaymaniyah and Baghdad regions $\left(59.82 \%\right.$ and $71.3 \%$ respectively) ${ }^{(2,16)}$. Our records were higher than records from neighboring countries. For example, the prevalence of brucellosis in Turkey and Saudi was $6 \%$ and $12.5 \%$ respectively ${ }^{(5,17)}$. Human brucellosis is still endemic in many parts of the world, such as Africa, Middle East, Latin America and Asia ${ }^{(18-20)}$. The main risk factors for 
brucellosis are the direct contact with infected animals and consumption of unpasteurized dairy products especially those which are locally made ${ }^{(21)}$. Additionally, many factors can play a significant role in the variation of the incidence of brucellosis, such as the demographic, occupational, and socioeconom-

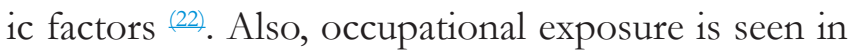
laboratory workers, veterinarians, farmers, and others who contact infected animals or tissues.

The age is one of the important risk factors for distribution the brucellosis worldwide. In the current study, the highest rate of brucellosis $(22.7 \%)$ was observed in the age group 21-30 years. Comparable findings were reported from different studies locally and worldwide $\stackrel{(3,23-25)}{ }$. This would be expected because the brucellosis is an occupational disease and this age group exposed longer to risk factors related to their occupation. Data revealed that people in certain occupation can get infected with brucellosis more than others $\stackrel{(26)}{\text {. }}$

The prevalence of brucellosis among females was significantly higher than males. This finding was in agreement with other studies in the region. Although some studies showed that more males were affected than females_(26,27), other studies revealed that the infection of brucellosis is predominant among females than males $\stackrel{(2,25,28)}{ }$. It is obvious in our region that females are more likely involved in household than males. Women are more concerned in domestic livestock and cows and other activities and as a consequence women may in greater risk to acquire the infection.

There were seasonal fluctuations in the incidence of brucellosis. The current study showed that the largest number of brucellosis cases were occurring in summer (July) while the lowest incidence occurred during winter (December). Similar seasonal pattern have been shown in several studies achieved locally and in neighboring countries ${ }^{2,4,26)}$. This seasonal pattern of brucellosis could be due to different factors for example summer season is the delivery (parturition) season of sheep and goats which increase the chance for direct contact with infected animals, their secretions could lead to infection through inhalation or accidental skin and mucous membrane penetration. Also, in summer season more opportunities for consumption of contaminated dairy products such as raw milk or fresh cheese which increase the chance of infection $\frac{(529)}{2}$.

\section{CONCLUSION}

Brucellosis is one of the important bacterial zoonotic diseases contributing to significant health and economic problems. It is a serious and debilitating disease that affects a variety of organs. Brucellosis is endemic in Duhok, Iraq. The incidence of the brucellosis is high and it remains a challenging health problem. Iraq has not been able to eradicate the disease and the population is still at great risk of acquiring it. The age, gender, seasonal changes are considered as important risk factors for the distribution of human brucellosis. Identifying the major risk factors for brucellosis will help to understand the nature of the disease and its transmission routes for eradication of human brucellosis. Furthermore, surveillance programs are essential to prevent and control brucellosis effectively. Also, the active screening for brucellosis will lead to early identification and consequently early initiation of therapy that will reduce the incidence of the brucellosis.

Conflict of interest: No conflicts of interest.

\section{Ethical clearance:}

The study was conducted with the approval of ethics committee in the Zakho Technical Institute, Duhok Polytechnic University, Duhok, Iraq. Permission was also obtained from the Azadi general hospital, Duhok. 


\section{REFERENCES}

1. Doganay, M. Human Brucellosis: Importance of Brucellosis. Recent Pat Antiinfect Drug Discov. 2013; 8(1):2-3.

https://doi.org/10.2174/1574891X11308010002

2. Al-Bayaa, Y.J. Epidemiology of Human Brucellosis among Populations in Iraq's Provinces in 2015. J Fac Med Baghdad. 2017; 58(2).

https://doi.org/10.32007/med.1936/ifacmedbagdad.v59i2.13

3. Yumuk, Z.; O'Callaghan, D. Brucellosis in Turkey - An Overview. Int J Infect Dis. 2012; 16(4):e22835. https://doi.org/10.1016/j.ijid.2011.12.011

4. Golshani, M.; Buozari, S. A review of Brucellosis in Iran: Epidemiology, Risk Factors, Diagnosis, Control, and Prevention. Iran Biomed J. 2017; 21(6):349-59.

5. Aloufi, A.D.; Memish, Z.A.; Assiri, A.M.; McNabb, S.J. Trends of Reported Human Cases of Brucellosis, Kingdom of Saudi Arabia, 20042012. J Epidemiol Glob Health. 2016; 6(1):11-8. https://doi.org/10.1016/j.jegh.2015.09.001

6. Acha, P.N.; Szfres, B. Zoonoses and Communicable Diseases Common to Man and Animals (Pan American Health Organization, Pan American Sanitary Bureau, Regional Office of the World Health Organization, Washington, DC), $2^{\text {nd }}$ Ed., 1987: pp. 579-591.

7. Alsubaie, S.; Almuneef, M.; Alshaalan, M.; Balkhy, H.; Albanyan, E.; Alola, S., et al. Acute Brucellosis in Saudi Families: Relationship Between Brucella Serology and Clinical Symptoms. Int J Infect Dis. 2005; 9(4):218-24.

https://doi.org/10.1016/j.iiid.2004.07.009

8. Franc, K.A.; Krecek, R.C.; Hasler, B.N.; Arenas-Gamboa, A.M. Brucellosis Remains a Neglected Disease in the Developing World: A Call For Interdisciplinary Action. BMC Public Health. 2018; 18(1):125.

https://doi.org/10.1186/s12889-017-5016-y

9. Rubach, M.P.; Halliday, J.E.; Cleaveland, S.; Crump, J.A. Brucellosis in Low-Income and Middle-Income Countries. Curr Opin Infect Dis. 2013; 26(5):404-12.

https://doi.org/10.1097/QCO.0b013e3283638104 10.Hegazy, Y.M.; Ridler, A.L.; Guitian, F.J. Assess- ment and Simulation of the Implementation of Brucellosis Control Programme in an Endemic Area of the Middle East. Epidemiol Infect. 2009; 137(10):1436-48.

https://doi.org/10.1017/S0950268809002301

11. Diaz, R.; Casanova, A.; Ariza, J.; Moriyon, I. The

Rose Bengal Test in Human Brucellosis: a Nglected Test for the Diagnosis of a Neglected Disease. PLoS Negl Trop Dis. 2011; 5(4):e950.

https://doi.org/10.1371/journal.pntd.0000950

12.Alton, G.G.; Jones, L.M.; Angus, R.D.; Verger, J.M. Techniques for the Brucellosis Laboratory. Paris, France: INRA. 1988.

13. Yohannes, M.; Gill, J.P.; Ghatak, S.; Singh, D.K.; Tolosa, T. Comparative Evaluation of the Rose Bengal Plate Test, Standard Tube Agglutination Test and Complement Fixation Test for the Diagnosis of Human Brucellosis. Rev Sci Tech. 2012; 31(3):979-84.

https://doi.org/10.20506/rst.31.3.2175

14. Morgan, W.J.; MacKinnon, D.J.; Lawson, J.R.; Cullen, G.A. The Rose Bengal Plate Agglutination Test in the Diagnosis of Brucellosis. Vet Rec. 1969; 85(23):636-41.

https://doi.org/10.1136/vr.85.23.636

15. Christopher, S.; Umapathy, B.L.; Ravikumar, K.L. Brucellosis: Review on the Recent Trends in Pathogenicity and Laboratory Diagnosis. J Lab Physicians. 2010; 2(2):55-60.

https://doi.org/10.4103/0974-2727.72149

16. Mohammed, I.S. Environmental, Efface and Filed Study for Source Brucella Disease. International Journal of Advanced Research. 2015; 3(7):17784.

17.Gül, S.; Satilmiş, Ö.; Ozturk, B.; Gökçe, M.I.; Kuscu, F. Seroprevalence of Brucellosis among Children in the Middle Anatolia Region of Turkey. Health Popul Nutr 2014; 32(4):577-9.

18. McDermott, J.; Grace, D.; Zinsstag, J. Economics of brucellosis impact and control in low-income countries. Rev Sci Tech. 2013; 32(1):249-61. https://doi.org/10.20506/rst.32.1.2197

19. Musallam, II; Abo-Shehada, M.N.; Hegazy, Y.M.; Holt, H.R.; Guitian, F.J. Systematic review of brucellosis in the Middle East: Disease Frequency in Ruminants and Humans and Risk Factors for Human Infection. Epidemiol Infect. 2016; 144(4):671- 
85. https://doi.org/10.1017/S0950268815002575 20.Lucero, N.E.; Ayala, S.M.; Escobar, G.I.; Jacob, N.R. Brucella Isolated in Humans and Animals in Latin America from 1968 to 2006. Epidemiol Infect. 2008; 136(4):496-503.

https://doi.org/10.1017/S0950268807008795

21. Asiimwe, B.B.; Kansiime, C.; Rwego, I.B. Risk Factors for Human Brucellosis in Agro-Pastoralist Communities of South Western Uganda: A Case-Control Study. BMC Res Notes. 2015; 8:405. https://doi.org/10.1186/s13104-015-1361-z

22.Dean, A.S.; Crump, L.; Greter, H.; Schelling, E.; Zinsstag, J. Global Burden of Human Brucellosis: A Systematic Review of Disease Frequency. PLoS Negl Trop Dis. 2012; 6(10):e1865. https://doi.org/10.1371/journal.pntd.0001865

23.Salari, M.H. Seroepidemiological Survey of Brucellosis Among Animal Farmers of Yazd Province. Iranian J Publ Health. 2002; 31(1-2):29-32.

24.Al-Tawfiq, J.A.; Abukhamsin, A. A 24-year Study of the Epidemiology of Human Brucellosis in a Health-Care System in Eastern Saudi Arabia. J Infect Public Health. 2009; 2(2):81-5. https://doi.org/10.1016/j.jiph.2009.03.003
25.Rasul, D.K.; Mansoor, I.Y. Seroprevalence of Human Brucellosis in Erbil city. Zanco J Med Sci. 2012; 16(3). https://doi.org/10.15218/zjms.2012.0038

26.Meky, F.A.; Hassan, E.A.; Abd Elhafez, A.M.; Aboul Fetouhl, A.M.; El-Ghazali, S.M. Epidemiology and Risk Factors of Brucellosis in Alexandria Governorate. East Mediterr Health J. 2007; 13(3):677-85.

27.Abdelbaset, A.E.; Abushahba, M.F.N.; Hamed, M.I.; Rawy, M.S. Sero-diagnosis of Brucellosis in Sheep and Humans in Assiut and El-Minya Governorates, Egypt. International Journal of Veterinary Science and Medicine. 2018; 6:S63-S7. https://doi.org/10.1016/j.ijvsm.2018.01.007

28.Al Mofleh, I.A.; Al Aska, A.I.; Al Sekait, M.A.; Al Balla, S.R.; Al Nasser, A.N. Brucellosis in Saudi Arabia: Epidemiology in the Central Region. Ann Saudi Med. 1996; 16(3):349-52. https://doi.org/10.5144/0256-4947.1996.349

29.Avdikou, I.; Maipa, V.; Alamanos, Y. Epidemiology of Human Brucellosis in a Defined Area of Northwestern Greece. Epidemiol Infect. 2005; 133(5):905-10. https://doi.org/10.1017/S0950268805003973 